Check for updates

Cite this: RSC Adv., 2019, 9, 12689

Received 4th December 2018

Accepted 12th March 2019

DOI: 10.1039/c8ra09985e

rsc.li/rsc-advances

\section{C-doped ZnO decorated with Au nanoparticles constructed from the metal-organic framework ZIF-8 for photodegradation of organic dyes}

\author{
Qiang-Qiang Chang, Yi-Wei Cui, Hai-Huan Zhang, Fei Chang, Bao-Hua Zhu \\ and Shi-Yong Yu iD *
}

Recently, engineering metal-organic frameworks (MOFs) into metal oxides by solid state thermal decomposition has attracted wide attention for photocatalytic applications. Here, a series of C-doped $\mathrm{ZnO}$ materials decorated with Au nanoparticles ( $\mathrm{Au} / \mathrm{C}-\mathrm{ZnO}$ ) were constructed via controlled pyrolysis of ZIF- 8 adsorbing different amounts of $\mathrm{HAuCl}_{4} \cdot 4 \mathrm{H}_{2} \mathrm{O}$. In this pyrolysis process, ZIF- 8 was transformed into $\mathrm{C}$-doped $\mathrm{ZnO}$ according to the EDX and XPS analysis. Meanwhile, $\mathrm{HAuCl}_{4} \cdot 4 \mathrm{H}_{2} \mathrm{O}$ was transformed into $\mathrm{Au}$ nanoparticles that were uniformly dispersed on the surface of $\mathrm{C}-\mathrm{ZnO}$ as seen in TEM images. The photocatalytic activity of as-prepared catalysts was evaluated by the degradation of methyl orange under UV-vis light irradiation. It was found that the photocatalytic activity of Au/C-ZnO was better than C-ZnO and pure $\mathrm{ZnO}$. Furthermore, Au/C-ZnO exhibited high photocatalytic stability. After three consecutive cycles, there was no noticeable deactivation in the reaction. This unusual photocatalytic activity was attributed to the synergistic effect of $\mathrm{C}$-doping and Au NPs.

\section{Introduction}

ZnO has been extensively studied for the photocatalytic degradation of organic dyes due to its excellent optical, electrical, catalytic activity, chemical stability and environmental friendliness. However, $\mathrm{ZnO}$ has a wide band gap $(\sim 3.3 \mathrm{eV})$ which can only be activated by ultraviolet (UV) light. Moreover, its rapid recombination rate of charge carriers limits its significant practical application in the photocatalysis field. ${ }^{1}$ Considerable efforts have been dedicated to improving the visible light response capacity and restrain recombination of photoinduced electron-hole pairs of single $\mathrm{ZnO}$ such as doping with metals and nonmetals, creating structural vacancies and combining with small-bandgap semiconductors. ${ }^{2-4}$

Among these, C-doped $\mathrm{ZnO}$ (C-ZnO) as an emerging visiblelight-responsive photocatalyst has attracted wide attention because $\mathrm{C}$ doping can narrow the band gap of $\mathrm{ZnO}$ by creating an intermediate energy level just above the valence band of ZnO. ${ }^{5}$ Importantly, C doping can also promote the separation of charge pairs. ${ }^{6} \mathrm{C}$-doped $\mathrm{ZnO}$ can be prepared by situ synthesis or post-treatment. However, the situ doping requires a critical synthesis condition, while post treatment leads to $\mathrm{C}$ only distribution of the surface of $\mathrm{ZnO}^{7}$

In addition, combining the plasmonic metal nanoparticles (NPs) with $\mathrm{ZnO}$ has been regarded as an effective approach to

Inner Mongolia Key Laboratory of Chemistry and Physics of Rare Earth Materials, School of Chemistry and Chemical Engineering, Inner Mongolia University, Hohhot 010021, Inner Mongolia, China.E-mail: syyunano@imu.edu.cn enhance the photocatalytic efficiency of the ZnO. On one hand, noble metal NPs have been shown to increase the efficiency of charge carrier separation of ZnO by forming Schottky junction with $\mathrm{ZnO}^{8}$ On the other hand, the surface plasmon resonance (SPR) effect of noble metal NPs can induced light absorption and forming stronger electronic filed. ${ }^{9}$

Recently, metal-organic-frameworks (MOFs) as precursors derived metal oxides have drawn considerable interest. Because the metal oxides derived from MOFs were inherited the porous structures of MOFs. ${ }^{10}$ Moreover, carbon modified metal oxides can be synthesized by using MOFs as precursor. ${ }^{11}$ ZIF-8 as a Zncontaining MOF can be easily synthesized using a rapid room temperature route without a stabilizing agent or activation processes. $^{12}$

In this paper, a series of Au nanoparticles decorated C-ZnO photocatalysts were constructed by simple one step solid-state pyrolysis of ZIF-8 adsorbing different amount of $\mathrm{HAuCl}_{4} \cdot 4 \mathrm{H}_{2} \mathrm{O}$ mixture (Fig. 1). The characteristics of the obtained photocatalysts were analyzed and the photocatalytic activities of the samples were evaluated by the photocatalytic degradation of methyl orange under UV-vis light irradiation. Furthermore, our work proposed alternative way to synthesized C doping metal oxides and noble metal decorated metal oxides.

\section{Experimental section}

\subsection{Chemicals}

Zinc nitrate hexahydrate $\left[\mathrm{Zn}\left(\mathrm{NO}_{3}\right)_{2} \cdot 6 \mathrm{H}_{2} \mathrm{O} \geq 99.0 \%\right]$, absolute methanol, ethyl alcohol $[\mathrm{EtOH} \geq 99.7 \%]$ and chloroauric acid 


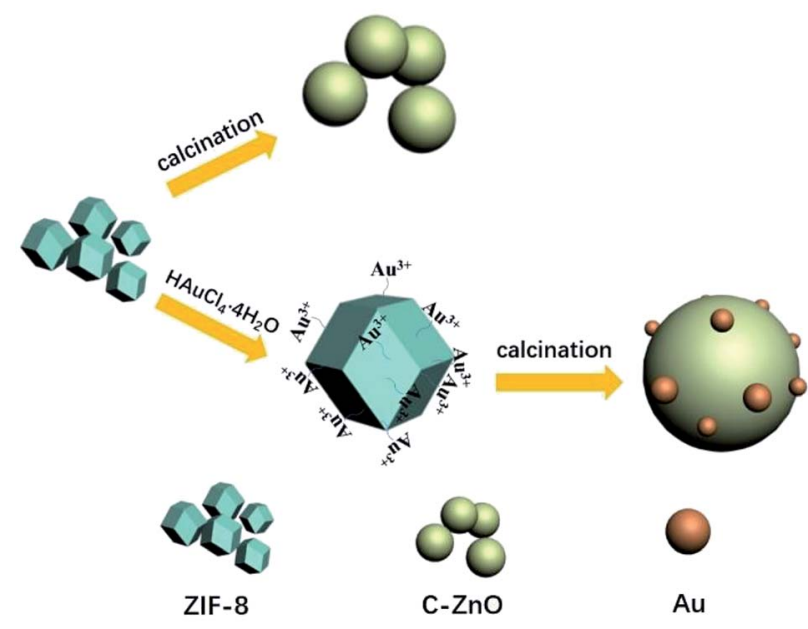

Fig. 1 Schematic illustration of $\mathrm{ZIF}-8$ derived $\mathrm{C}-\mathrm{ZnO}, \mathrm{Au} / \mathrm{C}-\mathrm{ZnO}$.

hydrated $\left[\mathrm{HAuCl}_{4} \cdot 4 \mathrm{H}_{2} \mathrm{O} \geq 98.0 \%\right.$ ] were purchased from Sinopharm Chemical Reagent Co., Ltd. Whereas 2-methylimidazole [H-MeIM] and methyl orange $[\mathrm{MO} \geq 96 \%]$ were obtained from Aladdin. All chemicals were used directly without any further purification. Distilled water was used throughout the experiments.

\subsection{Synthesis of ZIF-8 and its derived photocatalysts}

ZIF-8 was synthesized according to a previously reported method. ${ }^{13}$ Firstly, $\mathrm{Zn}\left(\mathrm{NO}_{3}\right)_{2} \cdot 6 \mathrm{H}_{2} \mathrm{O}(1 \mathrm{mmol})$ and H-MeIM (4 mmol) were dissolved in $25 \mathrm{~mL}$ methanol. Then the obtained solution was stirred $5 \mathrm{~min}$ and subsequently incubated without any interruption at room temperature for $24 \mathrm{~h}$. C-ZnO photocatalyst was synthesized via direct calcination ZIF-8 at $450{ }^{\circ} \mathrm{C}$ for $3 \mathrm{~h}$ with the heating rate of $5{ }^{\circ} \mathrm{C} \mathrm{min}^{-1}$. A series of $\mathrm{Au}$ nanoparticles decorated $\mathrm{C}-\mathrm{ZnO}$ photocatalysts were prepared by following method: firstly, $0.5 \mathrm{~g}$ ZIF- 8 powders were dispersed $20 \mathrm{ml}$ ethanol followed by the addition of different volume $\mathrm{HAuCl}_{4} \cdot 4 \mathrm{H}_{2} \mathrm{O}$ solution to make the ratio of $\mathrm{Au}$ and ZIF- 8 as $0.2 \mathrm{wt} \%, 0.3 \mathrm{wt} \%$ and $0.4 \mathrm{wt} \%$. The obtained suspension liquid was vigorous stirred for 60 min which make that the $\mathrm{Au}^{3+}$ sufficient adsorbed on the surface of ZIF-8. After that, the $\mathrm{HAuCl}_{4}$ modified ZIF-8 photocatalysts were collected by centrifugation and dried at $60{ }^{\circ} \mathrm{C}$. Finally, the obtained samples were treated by the preparation process of C-ZnO. The as-prepared samples were denoted as $\mathrm{Au} / \mathrm{C}-\mathrm{ZnO}(0.2 \mathrm{wt} \%)$, Au/C-ZnO $(0.3 \mathrm{wt} \%)$ and $\mathrm{Au} / \mathrm{C}-\mathrm{ZnO}(0.4 \mathrm{wt} \%)$ depending on the ratio of $\mathrm{Au}$ and $\mathrm{ZIF}-8$. The reference sample of $\mathrm{ZnO}$ was obtained by directly calcining $\mathrm{Zn}\left(\mathrm{NO}_{3}\right)_{2} \cdot 6 \mathrm{H}_{2} \mathrm{O}$ at $450{ }^{\circ} \mathrm{C}$ for $3 \mathrm{~h}$.

\subsection{Photocatalytic MO degradation}

The photocatalytic activities of the samples were evaluated by the photocatalytic degradation of methyl orange using a xenon lamp $(300 \mathrm{~W})$ as simulated sunlight. The distance between the lamp and reactor was $10 \mathrm{~cm}$. Typically, $50 \mathrm{mg}$ catalyst was dispersed in a $100 \mathrm{ml} 10 \mathrm{ppm}$ MO solution. Prior to the degradation, the suspensions were continuously stirred in the dark for 30 min to achieve adsorption-desorption equilibrium of between catalysts and MO molecules. At every 10 min intervals, $3 \mathrm{ml}$ suspensions was withdrawn, centrifuged and analyzed using UV-vis spectrometer at $462 \mathrm{~nm}$.

\subsection{Catalyst characterization}

The phases of as prepared photocatalysts were characterized by X-ray power diffraction (XRD) on a Rigaku DMAX2500 X-ray diffractometer using a copper target. Particle sizes and morphologies of the samples were determined using transmission electron microscopy (TEM), high resolution transmission electron microscopy (HRTEM) on a JEM-2010 apparatus with an acceleration voltage of $200 \mathrm{kV}$ and fieldemission scanning electron microscopy (FE-SEM, HITACHI S4800). Element distribution was obtained on energy-dispersive $\mathrm{X}$-ray spectroscopy (EDX). UV-vis diffuse reflectance spectra (UV-DRS) of the samples were measured using a Lambda 750 $\mathrm{UV} / \mathrm{Vis}$ spectrometer with $\mathrm{BaSO}_{4}$ act as the corrected baseline at room temperature. The photoluminescence (PL) spectra of the samples were recorded on Edinburgh Instruments FLS 920 spectrometer at an excitation wavelength of $320 \mathrm{~nm}$. Surface composition and chemical states were analyzed with a Thermo Scientific Escalab 250Xi X-ray photoelectron spectroscope (XPS) equipped with $\mathrm{Al} \mathrm{K} \alpha$ radiation, and the binding energy was calibrated by the $\mathrm{C} 1 \mathrm{~s}$ peak $(284.6 \mathrm{eV})$ of the contamination carbon.

\section{Results and discussion}

\subsection{Sample characterizations}

The X-ray diffraction (XRD) patterns of ZIF-8, ZnO, C-ZnO and $\mathrm{Au} / \mathrm{C}-\mathrm{ZnO}$ are shown in Fig. 2. Fig. 2a shows that the XRD pattern of as-synthesized ZIF-8 is identified to be similar to simulated ZIF-8. In addition, the sharp and strong peaks of assynthesized ZIF-8 indicate that it is well crystallized. Fig. $2 \mathrm{~b}$ shows the XRD patterns of ZnO and ZIF-8 derived C-ZnO and $\mathrm{Au} / \mathrm{C}-\mathrm{ZnO}(x)$ (" $x$ " symbol representing the mass ratio of $\mathrm{Au}$ and ZIF-8 of the precursor). After thermolysis, no ZIF-8 peaks could be found on the XRD patterns of ZIF- 8 derived C-ZnO and $\mathrm{Au} / \mathrm{C}$ $\mathrm{ZnO}(x)$, suggesting that the crystalline phase of ZIF-8 has been completely vanished. The typical diffraction peaks of the all samples at $2 \theta 31.7,34.4,36.2,47.5,56.6,62.8,67.9^{\circ}$ are ascribable to the (100), (002), (101), (102), (110), (103) and (102) reflections of ZnO (JCPDS 01-089-0511). In addition, a typical diffraction peak of Au NPs at $2 \theta 38.1^{\circ}$ can be found in the XRD patterns of $\mathrm{Au} / \mathrm{C}-\mathrm{ZnO}$ (0.4 wt\%). From the image of Fig. 2b, C$\mathrm{ZnO}$ and $\mathrm{Au} / \mathrm{C}-\mathrm{ZnO}(x)$ shows weaker diffraction intensity than $\mathrm{ZnO}$, implying that C-doped $\mathrm{ZnO}$ possesses lower crystallinity. Moreover, no diffraction peaks of carbon and other phase are observed in the XRD patterns of all samples.

Fig. 3 shows the EDX pattern of the C-ZnO sample, conforming that the sample contains the obvious signals of $\mathrm{Zn}, \mathrm{O}$, and $\mathrm{C}$ elements. No diffraction peaks of carbon were found in the XRD patterns of $\mathrm{C}-\mathrm{ZnO}$ which indicate that the carbon was doped in the lattice of $\mathrm{ZnO}$. 

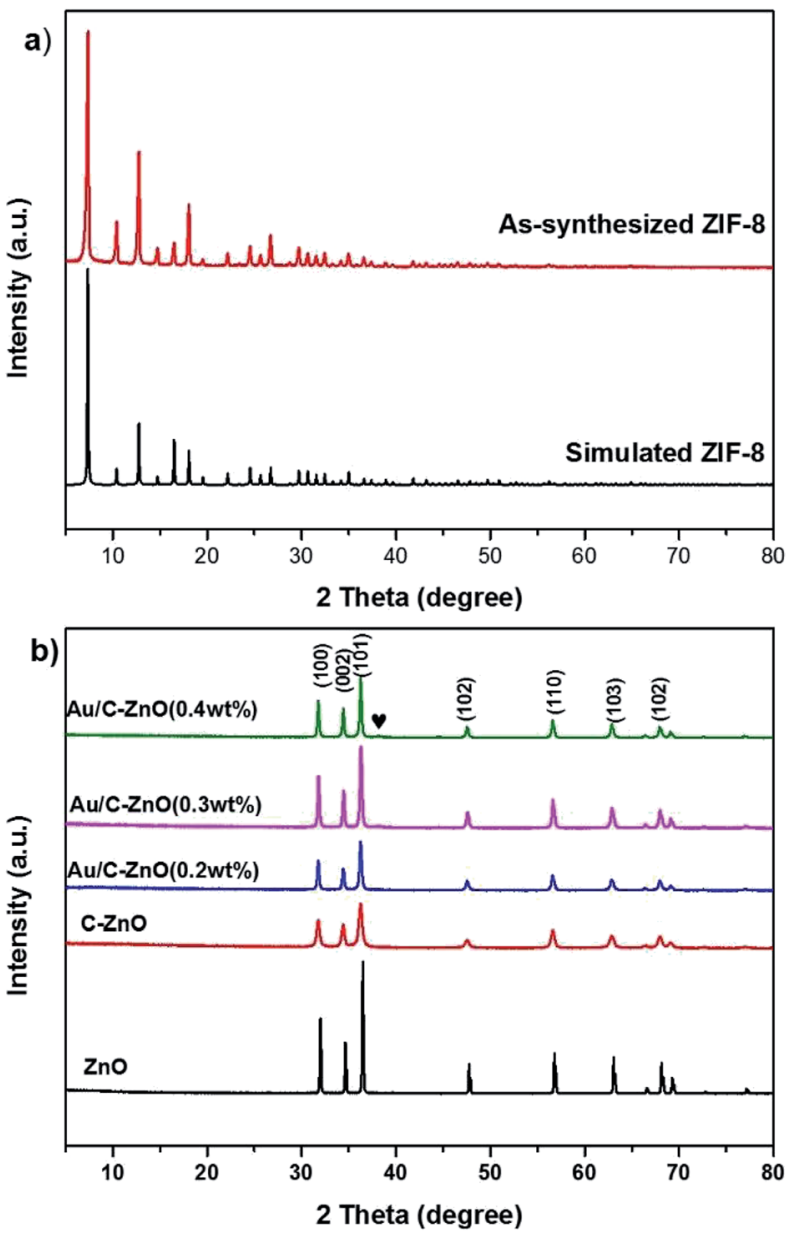

Fig. 2 XRD patterns of simulated ZIF- 8 and as-synthesized ZIF- 8 (a); $\mathrm{XRD}$ patterns of $\mathrm{ZnO}, \mathrm{C}-\mathrm{ZnO}, \mathrm{Au} / \mathrm{C}-\mathrm{ZnO}$ loaded different weight of $\mathrm{Au}$ (b).

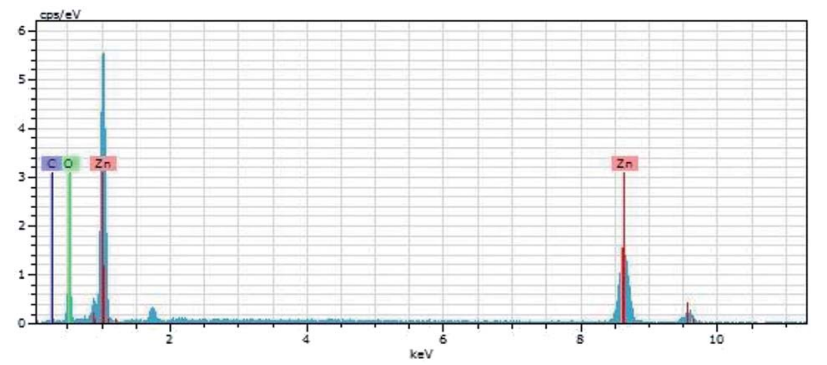

Fig. 3 EDX pattern of the C-ZnO.

XPS characterization were conducted to further verify the chemical composition and surface chemical state of the C-ZnO and $\mathrm{Au} / \mathrm{C}-\mathrm{ZnO}$, as depicted in Fig. 4. The typical XPS survey spectrum of C-ZnO (Fig. 4a) shows the presence of the elements $\mathrm{Zn}, \mathrm{O}$ and $\mathrm{C}$. The carbon content is 4.34\% (atomic\%) depending on the XPS of C-ZnO. As shown Fig. 4b, the high-resolution spectra of C1s can be fitted four peaks at a BE of 283.8, 284.6, 286.2 and $288.5 \mathrm{eV}$. These peaks observed at different BE correspond to various types of carbon bonding in the sample.
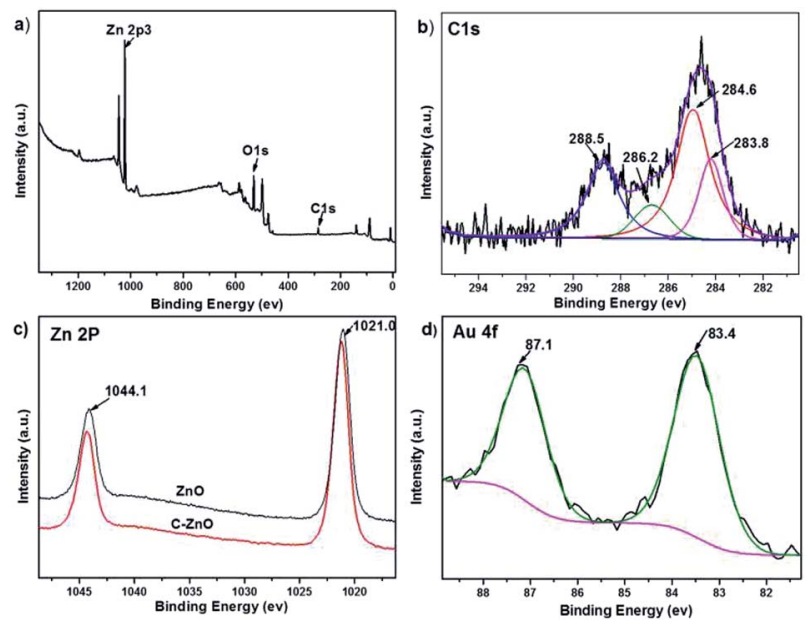

Fig. 4 Survey (a) and C1s (b) XPS spectra of C-ZnO, Zn 2p XPS spectra of $\mathrm{ZnO}$ and $\mathrm{C}-\mathrm{ZnO}$ (c) and $\mathrm{Au} 4 \mathrm{f}$ XPS spectra of $\mathrm{Au} / \mathrm{C}-\mathrm{ZnO}(0.3 \mathrm{wt} \%$ ) (d).

The main peak at $284.6 \mathrm{eV}$ is attributed to the adventitious hydrocarbon. The peaks at $283.8 \mathrm{eV}$ and $286.2 \mathrm{eV}$ are due to $\mathrm{Zn}-$ $\mathrm{O}-\mathrm{C}$ and $\mathrm{Zn}-\mathrm{C}$ bonds, respectively. ${ }^{\mathbf{1 4}}$ However, the peak locates at $288.5 \mathrm{eV}$ is attributed to the adsorbed $\mathrm{CO}_{2}$ and structural carbonate species containing $\mathrm{C}=\mathrm{O}$. As shown Fig. 4c, BEs of $1021.0 \mathrm{eV}$ and $1044.1 \mathrm{eV}$ for bare $\mathrm{ZnO}$ were assigned to $\mathrm{Zn} 2 \mathrm{p}_{3 / 2}$ and $2 \mathrm{p}_{5 / 2}$. It can be clearly seen that the $\mathrm{BE}$ of $\mathrm{Zn} 2 \mathrm{p}$ in $\mathrm{C}-\mathrm{ZnO}$ are blue shifted $(0.2 \mathrm{eV})$ systematically relative to pure $\mathrm{ZnO}$, which was due to the different chemical interactions present in both samples. The BE difference between $\mathrm{Zn} 2 \mathrm{p}_{3 / 2}$ and $2 \mathrm{p}_{5 / 2}$ XPS lines remains $23.1 \mathrm{eV}$ for $\mathrm{C}-\mathrm{ZnO}$ and $\mathrm{ZnO}$, suggesting $\mathrm{Zn}$ is in $\mathrm{Zn}^{2+}$ state in the C-ZnO sample. ${ }^{14}$ The $\mathrm{Au} 4 \mathrm{f}$ XPS spectrum of Au/C$\mathrm{ZnO}(0.3 \mathrm{wt} \%)$ was presented in Fig. $4 \mathrm{~d}$. Two peaks at the BEs of 83.4 and $87.1 \mathrm{eV}$, respectively, assigned to $\mathrm{Au} 4 \mathrm{f}_{7 / 2}$ and $\mathrm{Au} 4 \mathrm{f}_{5 /}$ ${ }_{2}$, indicating that the Au species in the sample were presented in the metallic state. ${ }^{15}$ From the EDX and XPS analyze, ZIF-8 was successfully transformed $\mathrm{C}$ doped $\mathrm{ZnO}$ during the pyrolysis process of ZIF-8.

From the SEM of ZIF-8 (Fig. 5), it was exhibited as regular dodecahedral morphology with the size of $\sim 100 \mathrm{~nm}$. TEM was used to further analyze the morphology and structures of the catalyst. Fig. 6a-f show the TEM images of C-ZnO and Au/C-ZnO (0.3 wt\%). ZIF-8 derived C-ZnO are presented irregular nanoparticles with size of 50-150 nm (Fig. 6a and b). The HRTEM image of $\mathrm{C}-\mathrm{ZnO}$ are presented in Fig. $6 \mathrm{c}$ in which the lattice spacing of ca. $0.247 \mathrm{~nm}$ is assigned to the (101) plane of ZnO.

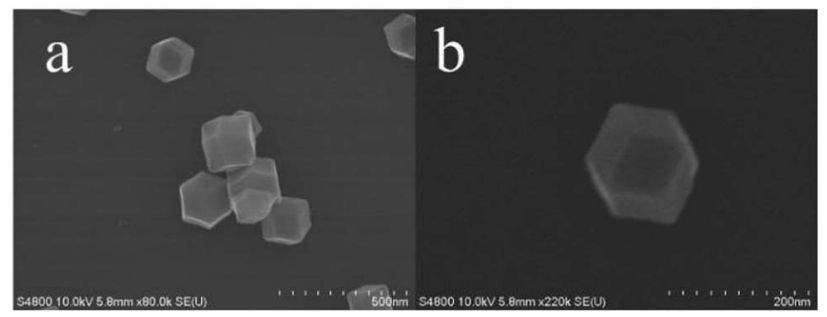

Fig. 5 SEM images of ZIF-8. 


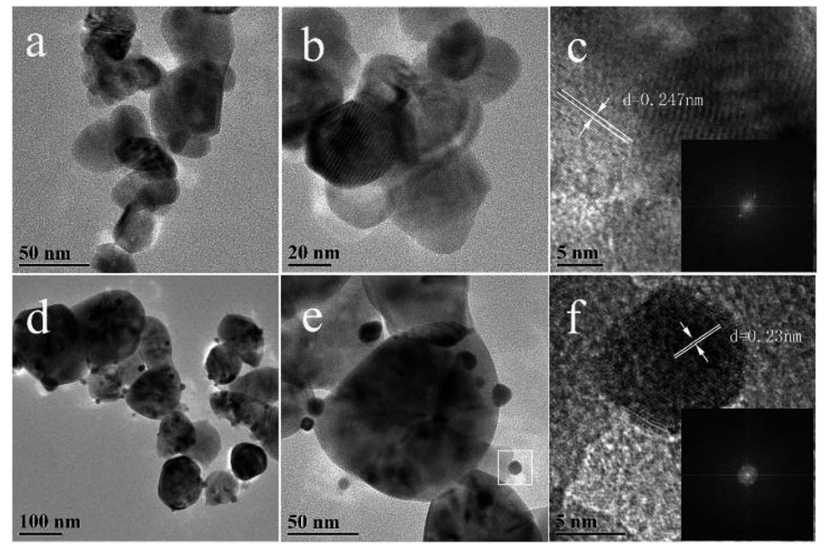

Fig. 6 TEM ( $a$ and $b$ ) and HRTEM (c) images of $\mathrm{C}-\mathrm{ZnO}$ (inset in the $\mathrm{c}$ is corresponding FFT image of $c$ ); TEM ( $d$ and e) and HRTEM (f) images of $\mathrm{Au} / \mathrm{C}-\mathrm{ZnO}(0.3 \mathrm{wt} \%$ ) (inset in the $\mathrm{f}$ is corresponding to FFT image of $\mathrm{f}$ ).

ZIF-8 derived $\mathrm{Au} / \mathrm{C}-\mathrm{ZnO}(0.3 \mathrm{wt} \%)$ is showed in Fig. $6 \mathrm{~d}-\mathrm{f}$. The $\mathrm{Au}$ nanoparticles with the size of $\sim 10 \mathrm{~nm}$ can be found to be well dispersed on the surface of $\mathrm{C}-\mathrm{ZnO}$. The lattice spacing of $c a$. $0.23 \mathrm{~nm}$ is observed in Fig. 6f which corresponds to the (111) plane of $\mathrm{Au}$, which indicates that the $\mathrm{HAuCl}_{4}$ molecules were decomposed into Au nanoparticles.

UV-vis diffuse adsorption spectra (UV-DRS) of ZIF-8 derived $\mathrm{C}-\mathrm{ZnO}$ and $\mathrm{Au} / \mathrm{C}-\mathrm{ZnO}(x)$ were shown in Fig. 7a. In comparison with ZnO, C-ZnO displays an obvious red-shift of optical bandgap absorption edge into visible-light region. The band gap energy $\left(E_{\mathrm{g}}\right)$ of $\mathrm{ZnO}$ and $\mathrm{C}-\mathrm{ZnO}$ was calculated from a plot of $(\alpha h \nu)^{2} v s$. $(h \nu)$ according to Kubelka-Munk rule as shown in Fig. 7b. The band gap value of the $\mathrm{ZnO}$ and $\mathrm{C}-\mathrm{ZnO}$ was measured about $3.08 \mathrm{eV}$ and $3.02 \mathrm{eV}$, respectively. The narrowing band gap of C-doped $\mathrm{ZnO}$ is mainly induced by the $\mathrm{C}$ doping. Z. Jiang et al. ${ }^{\mathbf{1 6}}$ reported $\mathrm{C}$ doping not only expands the $\mathrm{VB}$ width of $\mathrm{ZnO}$ but also lifts its valance band maximum (VBM) energy. Furthermore, Au/C-ZnO $(x)$ exhibited a higher absorption in the visible region compare to the $\mathrm{C}-\mathrm{ZnO}$ which was due to the absorption of the Au surface plasmon resonance (SPR).

\subsection{Photocatalytic degradation of MO}

Photocatalytic activity of the as-prepared catalysts was investigated by the photocatalytic degradation of MO using a xenon lamp $(300 \mathrm{~W})$ as simulated sunlight. As shown in Fig. 8a, the pure $\mathrm{ZnO}$ showed poor photocatalytic activity with only $6 \% \mathrm{MO}$ degradation. However, C-ZnO showed 76\% MO degradation in 80 min. Obviously, ZIF-8 derived $\mathrm{Au} / \mathrm{C}-\mathrm{ZnO}$ showed higher photocatalytic degradation of $\mathrm{MO}$ than $\mathrm{C}-\mathrm{ZnO}$ and $\mathrm{ZnO}$. It was also found that the photocatalytic activity of $\mathrm{Au} / \mathrm{C}-\mathrm{ZnO}$ was depended on the ratio of $\mathrm{HAuCl}_{4}$ and ZIF-8 of precursor. $92.3 \%$ and $95 \%$ of $\mathrm{MO}$ was degraded by the $\mathrm{Au} / \mathrm{C}-\mathrm{ZnO}(0.2 \mathrm{wt} \%)$ and $\mathrm{Au} / \mathrm{C}-\mathrm{ZnO}(0.4 \mathrm{wt} \%)$ in 80 min under light irradiation, respectively. However, $100 \% \mathrm{MO}$ was degraded by the $\mathrm{Au} / \mathrm{C}-\mathrm{ZnO}$ $(0.3 \mathrm{wt} \%)$ in only $70 \mathrm{~min}$. This phenomenon also can be found in Fig. 8b in which the intensity of the absorption peak of MO is decreased gradually with the irradiation time increasing
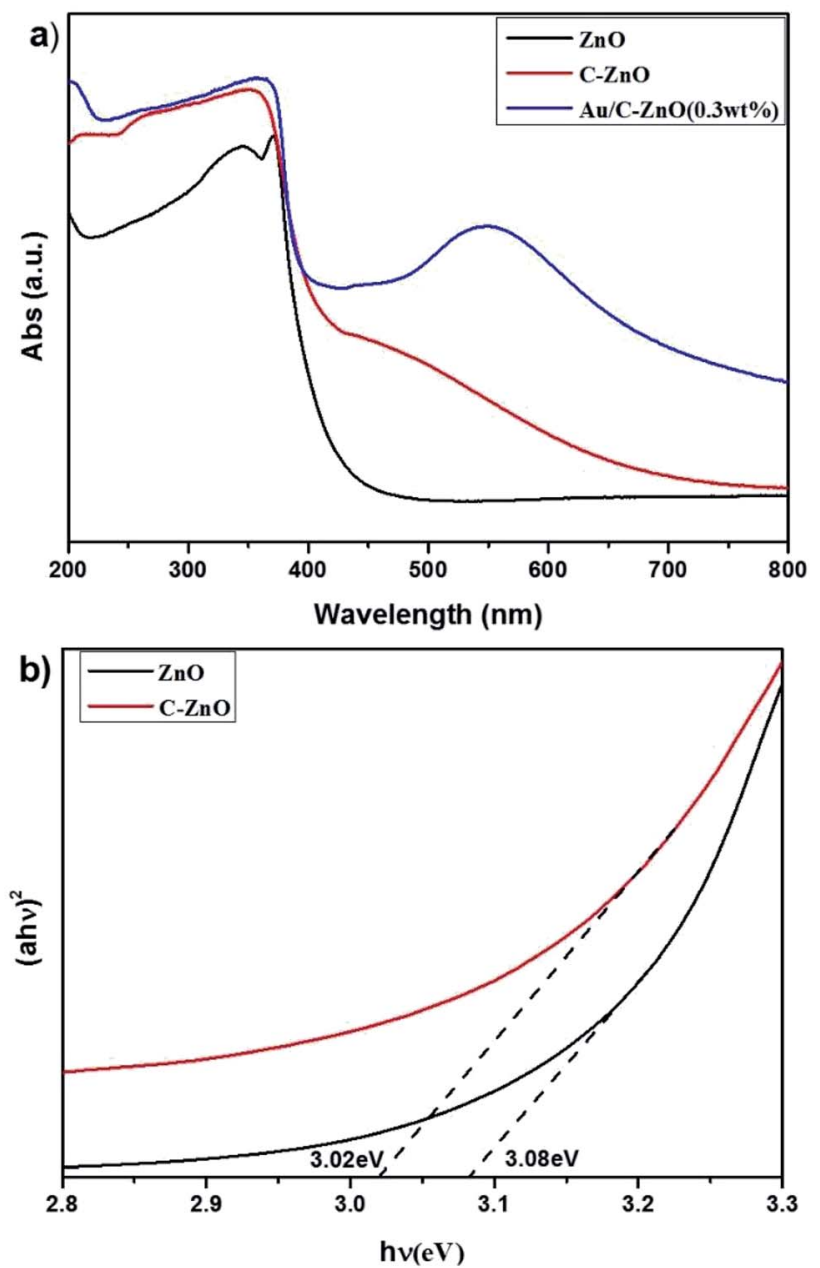

Fig. 7 UV-vis diffuse adsorption spectra of the $\mathrm{ZnO}, \mathrm{C}-\mathrm{ZnO}$ and $\mathrm{Au} / \mathrm{C}$ $\mathrm{ZnO}(x)(a)$ and corresponding $(\alpha h \nu)^{2} v s$. hv plots for $\mathrm{ZnO}$ and $\mathrm{C}-\mathrm{ZnO}$ (b).

and the color of MO gradually changed from orange into no color.

\subsection{Stability of photocatalyst}

To evaluate the stability of $\mathrm{Au} / \mathrm{C}-\mathrm{ZnO}(0.3 \mathrm{wt} \%)$, cycling experiments were carried out on MO degradation under light irradiation for three times. After three consecutive cycle's reactions, the photocatalytic activity of $\mathrm{Au} / \mathrm{C}-\mathrm{ZnO}(0.3 \mathrm{wt} \%)$ no significant decreased indicating the high stabilization of $\mathrm{Au} / \mathrm{C}-\mathrm{ZnO}$ (Fig. 9a). The outstanding stability of the ZIF-8 derived Au/C$\mathrm{ZnO}$ was further determined by analyzing the XRD patterns of before and after reaction (Fig. 9b). The results revealed that phase structure of $\mathrm{Au} / \mathrm{C}-\mathrm{ZnO}(0.3 \mathrm{wt} \%)$ maintained intact after three recycling reaction.

\subsection{Mechanism of enhanced photocatalytic activity}

In order to reveal the underlying reaction mechanism on the enhanced photocatalytic activity of $\mathrm{Au} / \mathrm{C}-\mathrm{ZnO}(0.3 \mathrm{wt} \%)$ in detail, the free radical and holes generation during the process of photocatalytic degradation of $\mathrm{MO}$ over $\mathrm{Au} / \mathrm{C}-\mathrm{ZnO}(0.3 \mathrm{wt} \%)$ were investigated by adding various scavengers or in the absence of $\mathrm{O}_{2}$. As shown in Fig. 10a, it can be seen that 

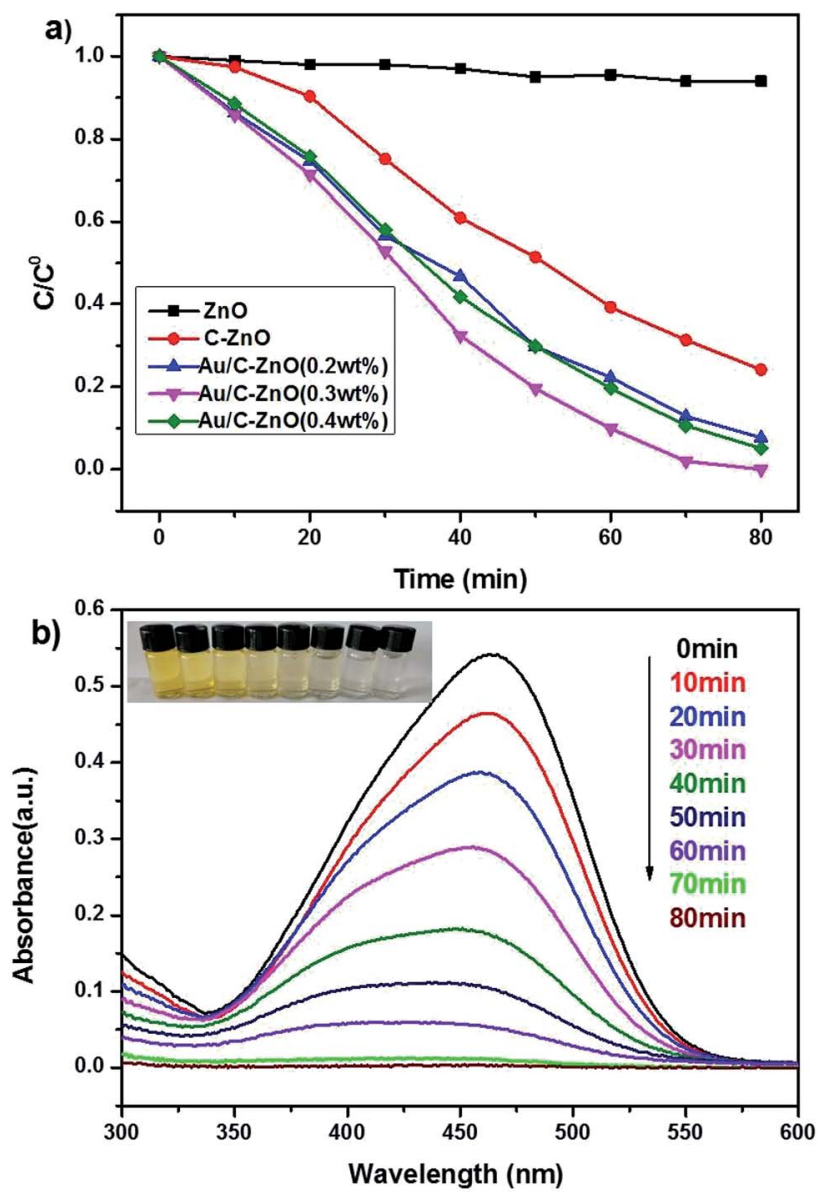

Fig. 8 Photocatalytic degradation of $\mathrm{MO}$ by $\mathrm{ZnO}, \mathrm{C}-\mathrm{ZnO}$ and $\mathrm{Au} / \mathrm{C}$ $\mathrm{ZnO}(\mathrm{x})(\mathrm{a})$; time dependent UV-vis absorption spectrum showing the photocatalytic degradation of $\mathrm{MO}$ by $\mathrm{Au} / \mathrm{C}-\mathrm{ZnO}(0.3 \mathrm{wt} \%$ ) (catalyst dose: $30 \mathrm{mg}, 320 \mathrm{~nm}<\lambda<780 \mathrm{~nm}$, [MO]: $10 \mathrm{ppm}$, volume: $100 \mathrm{~mL}$ ) (b).

controlled experiment in the inert $\mathrm{N}_{2}$ atmosphere. A dramatic decreasing in the photocatalytic activity was observed indicating that the $\mathrm{O}_{2}$ or $\cdot \mathrm{O}_{2}{ }^{-}$play an important role in the photocatalytic degradation process compared with in air atmosphere under light irradiation. When addition of $t-\mathrm{BuOH}$ as an $\cdot \mathrm{OH}$ scavenger ${ }^{17}$ and $\mathrm{AO}$ as an $\mathrm{h}^{+}$scavenger, ${ }^{18}$ the photodegradation rate of $\mathrm{MO}$ also be suppressed suggesting that $\cdot \mathrm{OH}$ and $\mathrm{h}^{+}$also participated the photodegradation process of MO.

The separation efficiency of charge carrier is one of the most key factors for photocatalytic activity. Photoluminescence (PL) spectra is always studied the photoelectron transfer and recombination. ${ }^{19}$ As shown in Fig. 10b, the main emission peak is observed at around $612 \mathrm{~nm}$ for the $\mathrm{ZnO}, \mathrm{C}-\mathrm{ZnO}$ and $\mathrm{Au} / \mathrm{C}-\mathrm{ZnO}$ ( $0.3 \mathrm{wt} \%$ ) excited at $320 \mathrm{~nm}$. The ZIF-8 derived C-ZnO exhibits a lower PL intensity than $\mathrm{ZnO}$, because the $\mathrm{C}$ doping can accelerate the separation of photogenerated electron and hole pairs. In addition, ZIF-8 derived Au/C-ZnO (0.3 wt\%) shows the lowest emission peak among the $\mathrm{ZnO}$ and $\mathrm{C}-\mathrm{ZnO}$, which indicated incorporation of $\mathrm{Au}$ NPs further lead to the charge transfer. The reduction of emission peak is due to the electron sink effect where the Au NPs act as electron trap to gather photoelectron of C-ZnO and suppress the recombination of
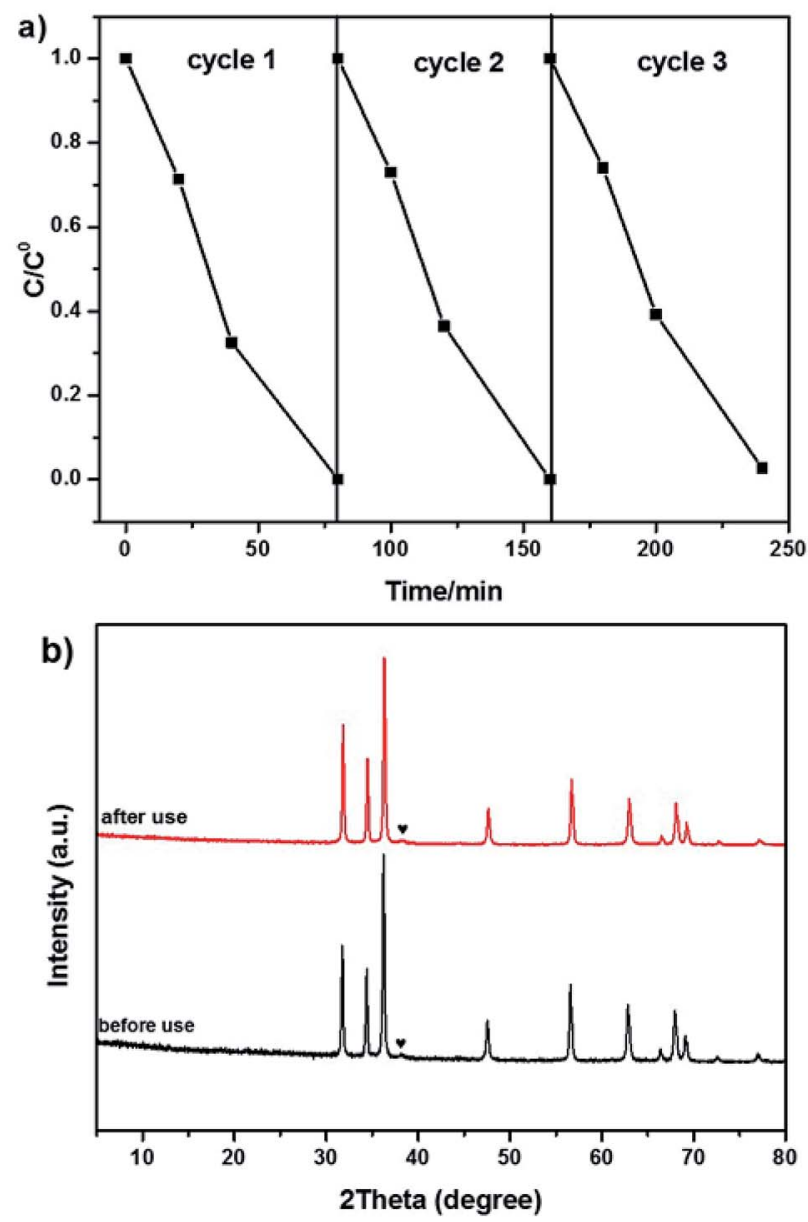

Fig. 9 Cycling runs for the photocatalytic degradation of $\mathrm{MO}$ over $\mathrm{Au} /$ $\mathrm{C}-\mathrm{ZnO}(0.3 \mathrm{wt} \%)(\mathrm{a})$; XRD patterns of $\mathrm{Au} / \mathrm{C}-\mathrm{ZnO}$ (0.3 wt\%) before and after photocatalytic reaction (b).

photogenerated electron and hole pairs during illumination by forming a Schottky barrier between Au NPs and C-ZnO.

Fig. 11 shows the schematic diagram for the photocatalytic degradation $\mathrm{MO}$ over $\mathrm{Au} / \mathrm{C}-\mathrm{ZnO}$. When $\mathrm{ZnO}$ was doped $\mathrm{C}$, the new additional bandgap electron states were appeared at VBM (valance band maximum) arising from C-doping, which expanded visible-light-response of $\mathrm{ZnO}^{16}$ Under light irradiation, C-ZnO can be excited to promote the valence band electrons up to the conduction band and leaving holes in the valence band by part of visible light. Considering the lower Fermi level of Au NPs, the photo-generated electrons in the CB of C-ZnO can be easily transferred to Au NPs. ${ }^{20}$ In addition, the SPR of Au NPs can't be ignored for the significantly improved photocatalytic performance, which can be induced to generate energetic plasmonic electrons at around $\sim 550 \mathrm{~nm}$ visible light. Due to the high energy position of the SPR state of Au NPs, the excited energetic plasmonic electrons subsequently injected into the $\mathrm{CB}$ of C-ZnO. ${ }^{21,22}$ The photo-generated electrons and the excited energetic plasmonic electrons would react with adsorbed $\mathrm{O}_{2}$ to form $\cdot \mathrm{O}_{2}{ }^{-}$. However, the leaving holes in the valence band of $\mathrm{C}-\mathrm{ZnO}$ would react with adsorbed $\mathrm{OH}^{-}$or water molecule to form $\cdot \mathrm{OH}$. The generated $\cdot \mathrm{O}_{2}^{-}, \cdot \mathrm{OH}$ and $\mathrm{h}^{+}$can mineralize MO molecules. 

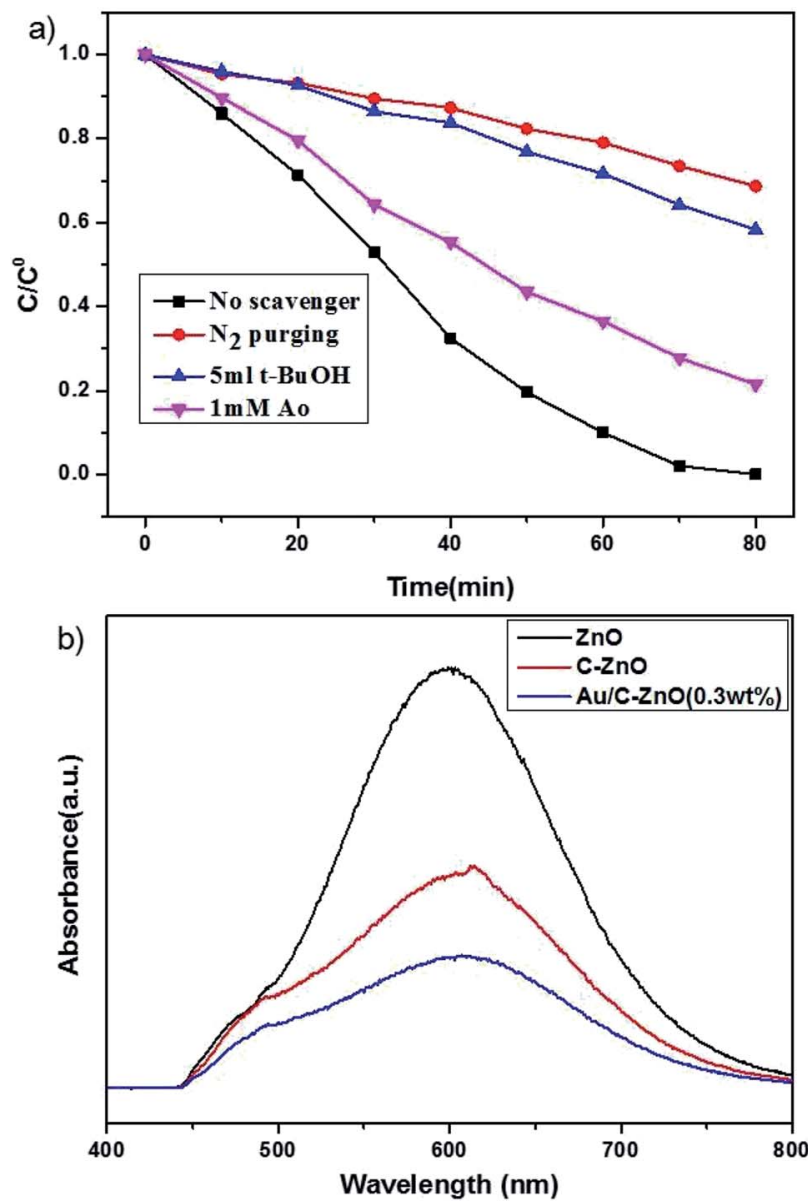

Fig. 10 Influence of various scavengers on the photocatalytic activity of $\mathrm{Au} / \mathrm{C}-\mathrm{ZnO}(0.3 \mathrm{wt} \%)$ toward the degradation of $\mathrm{MO}$ (catalyst dose: $30 \mathrm{mg}, 320 \mathrm{~nm}<\lambda<780 \mathrm{~nm}$, [MO]: $10 \mathrm{ppm}$, volume: $100 \mathrm{~mL})(\mathrm{a})$; photoluminescence emission spectra of the $\mathrm{ZnO}, \mathrm{C}-\mathrm{ZnO}$ and $\mathrm{Au} / \mathrm{C}$ $\mathrm{ZnO}(0.3 \mathrm{wt} \%)(\mathrm{b})$.

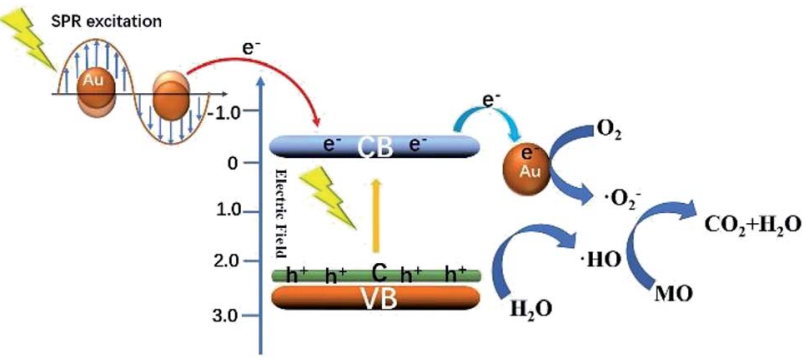

Fig. 11 Schematic diagram showing the photocatalytic degradation $\mathrm{MO}$ over $\mathrm{Au} / \mathrm{C}-\mathrm{ZnO}$ under light irradiation.

\section{Conclusions}

In summary, $\mathrm{Au} / \mathrm{C}-\mathrm{ZnO}$ hybrid nanostructures were fabricated by a-step calcination $\mathrm{HAuCl}_{4} \cdot 4 \mathrm{H}_{2} \mathrm{O}$ treated $\mathrm{ZIF}-8$. It was found that $\mathrm{C}$ was doped in $\mathrm{ZnO}$ lattice and $\mathrm{Au}$ NPs were uniformly loaded onto $\mathrm{C}-\mathrm{ZnO}$ by this method. The as-prepared $\mathrm{Au} / \mathrm{C}-\mathrm{ZnO}$ showed enhanced photocatalytic degradation of MO than C$\mathrm{ZnO}$ and $\mathrm{ZnO}$. The improved photocatalytic activity was attribute to the synergistic effect of C-doping and Au NPs, where C-doping and SPR of Au NPs can improve the visible-light response of $\mathrm{ZnO}$. Moreover, the formation of Schottky barrier between the $\mathrm{C}-\mathrm{ZnO}$ and $\mathrm{Au}$ NPs can efficiently accelerate the electron transfer. The ratio of Au and ZIF-8 in the precursor also affected the photocatalytic activity. The optimal hybrid nanostructure for photocatalytic degradation of MO was determined to be $\mathrm{Au} / \mathrm{C}-\mathrm{ZnO}$ (0.3 wt\%). Furthermore, Au/C-ZnO exhibited high photocatalytic stability. After three cycle's reactions, the $\mathrm{Au} / \mathrm{C}-\mathrm{ZnO}$ (0.3 wt\%) showed no significant decrease on photocatalytic degradation of MO. The outstanding photocatalytic activity of $\mathrm{Au} / \mathrm{C}-\mathrm{ZnO}$ make it an effective way to degrade organic dyes.

\section{Conflicts of interest}

There are no conflicts to declare.

\section{Acknowledgements}

This work was supported by the National Natural Science Foundation of China (Grant No. 21661024), the Open Funds of the State Key Laboratory of Rare Earth Resource Utilization (Grant No. RERU2017009), Inner Mongolia Scientific Research projects (Grant No. NJZZ14003) and Inner Mongolia University Student' Platform for Innovation and Entrepreneurship Training Program.

\section{References}

1 S. J. Pearton, D. P. Norton, K. Ip, Y. W. Heo and T. Steiner, Superlattices Microstruct., 2005, 34, 3-32.

2 A. Kubacka, M. Fernández-García and G. Colón, Chem. Rev., 2012, 112, 1555-1614.

3 R. Georgekutty, M. K. Seery and S. C. Pillai, J. Phys. Chem. C, 2008, 112, 13563-13570.

4 D. Chen, Z. Wang, T. Ren, H. Ding, W. Yao, R. Zong and Y. Zhu, J. Phys. Chem. C, 2014, 118, 15300-15307.

5 Y. G. Lin, Y. K. Hsu, Y. C. Chen, L. C. Chen, S. Y. Chen and K. H. Chen, Nanoscale, 2012, 4, 6515-6519.

6 W. Yu, J. Zhang and T. Peng, Appl. Catal., B, 2016, 181, 220227.

7 P. Liang, C. Zhang, H. Sun, S. Liu, M. O. Tade and S. Wang, Energy Fuels, 2017, 31, 2138-2143.

8 T. C Damato, C. C. S. D. Oliveira, R. A. Ando and P. H. C. Camargo, Langmuir, 2013, 29, 1642-1649.

9 E. Ha, L. Y. S. Lee, H. W. Man, S. C. E. Tsang and K. Y. Wong, ACS Appl. Mater. Interfaces, 2015, 7, 9072-9077.

10 Y. V. Kaneti, J. Tang, R. R. Salunkhe, X. Jiang, A. Yu, K. C. W. Wu and Y. Yamauchi, Adv. Mater., 2017, 29, 1604898.

11 L. Pan, T. Muhammad, L. Ma, Z. F. Huang, S. Wang and L. Wang, Appl. Catal., B, 2016, 189, 181-191.

12 J. Cravillon, S. Münzer, S. J. Lohmeier, A. Feldhoff, K. Huber and M. Wiebcke, Chem. Mater., 2009, 21, 1410-1412.

13 S. R. Venna, J. B. Jasinski and M. A. Carreon, J. Am. Chem. Soc., 2010, 132, 18030-18033. 
14 D. K. Mishra, J. Mohapatra, M. K. Sharma, R. Chattarjee, S. K. Singh, S. Varma, S. N. Behera, S. K. Nayak and P. Entel, J. Magn. Magn. Mater., 2013, 329, 146-152.

15 J. Yang, X. Wang, Y. Chen, J. Dai and S. Sun, RSC Adv., 2015, 5, 9771-9782.

16 A. S. Alshammari, L. Chi, X. Chen, A. Bagabas, D. Kramer, A. Alromaeh and Z. Jiang, RSC Adv., 2015, 5, 27690-27698.

17 L. Jing, Y. Qu, B. Wang, S. Li, B. Jiang, L. Yang, W. Fu, H. Fu and J. Sun, Sol. Energy Mater. Sol. Cells, 2006, 90, 1773-1787.
18 M. Xu, H. Niu, J. Huang, J. Song, C. Mao, S. Zhang, C. Zhu and C. Chen, Appl. Surf. Sci., 2015, 351, 374-381.

19 G. P. Singh, K. M. Shrestha, A. Nepal, K. J. Klabunde and C. M. Sorensen, Nanotechnology, 2014, 25, 265701.

20 J. Hu, N. You, Z. Yu, G. Zhou and X. Xu, J. Appl. Phys., 2016, 120, 74-6206.

21 W. He, H. K. Kim, W. G. Wamer, D. Melka, J. H. Callahan and J. J. Yin, J. Am. Chem. Soc., 2014, 136, 750-757.

22 J. Lee, S. Mubeen, X. Ji, G. D. Stucky and M. Moskovits, Nano Lett., 2012, 12, 5014-5019. 